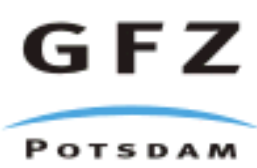

Originally published as:

Klemann, V., Ivins, E.R., Martinec, Z., Wolf, D. (2007): Models of active glacial isostasy roofing warm subduction: Case of the South Patagonian Ice Field. - Journal of Geophysical Research, 112, B09405,

DOI: 10.1029/2006JB004818. 


\section{Models of Active Glacial Isostasy Roofing Warm Subduction: The Case of the South Patagonian Ice Field}

Volker Klemann, ${ }^{1}$ Erik R. Ivins, ${ }^{2}$ Zdeněk Martinec, ${ }^{1,3}$ and Detlef Wolf ${ }^{1,4}$

V. Klemann, GeoForschungsZentrum Potsdam, Department 1: Geodesy and Remote Sensing, Telegrafenberg, D-14473 Potsdam, Germany (volkerk@gfz-potsdam.de)

E.R. Ivins, Jet Propulsion Laboratories California Institute of Technology, 4800 Oak Grove Dr., Pasadena, CA 91109-8099 (Erik.R.Ivins@jpl.nasa.gov)

Z. Martinec, Department of Geophysics, Faculty of Mathematics and Physics, Charles University in Prague, v Holešovičkách 2, 18000 Prague, Czech Republic; GeoForschungsZentrum Potsdam, Department 1, Geodesy and Remote Sensing, Telegrafenberg, D-14473 Potsdam, Germany (zdenek@gfz-potsdam.de)

D. Wolf, Geodetic Institute, Stuttgart University, Geschwister-Scholl-Str. 24D, 70174 Stuttgart, Germany; GeoForschungsZentrum Potsdam, Department 1, Geodesy and Remote Sensing, Telegrafenberg, D-14473 Potsdam, Germany (dasca@gfz-potsdam.de)

${ }^{1}$ GeoForschungsZentrum Potsdam,

Geodesy and Remote Sensing,

Telegrafenberg, Potsdam, Germany

${ }^{2}$ Jet Propulsion Laboratory, California

Institute of Technology, Pasadena,

California, USA

${ }^{3}$ Charles University in Prague,

Department of Geophysics, Prague, Czech

Republic

${ }^{4}$ Stuttgart University, Geodetic Institute,

Stuttgart, Germany 
Abstract. Modern geodetic techniques such as precise Global Positioning System (GPS) and high resolution space gravity mapping (GRACE) make it possible to measure the present-day rate of viscoelastic gravitational Earth response to present and past glacier-mass changes. The Andes of Patagonia contain glacial environments of dramatic mass change. These mass-load changes occur near a tectonically active boundary between the Antarctic and South American plates. The mechanical strength of the continental side of this boundary is influenced by Neogene ridge subduction and by the subduction of a youthful oceanic slab. A ridge of young volcanos parallel the Pacific coastline. Release of volatiles (such as water) at depth along this ridge create a unique rheological environment. To assess the influence of this rheological ridge structure on the observational land uplift rate we apply a two-dimensional viscoelastic earth model. A numerical study is presented which examines the sensitivity of glacial loading-unloading response to the complex structure at depth related to the subducting slab, the viscous wedge between slab and continental lithosphere and the increase of elastic thickness from oceanic to continental lithosphere. A key feature revealed by our numerical experiments is a continuum flow wherein the slab subdues the material transport toward oceanic mantle and crust. The restricted flow is sensitive to the details of slab mechanical strength and penetration into the upper mantle. The reduced viscosity within the mantle wedge, however, enhances the load-induced material transport everywhere within the asthenosphere. 


\section{Introduction}

The southernmost Andes of South America experienced dramatic changes in glacier mass during the Pleistocene and are in rapid demise at present time (PT). Ivins and James [2004] have reported that the land uplift in Patagonia measured by Bevis et al. [2002] is appropriately modeled by the response of the viscoelastic earth. However, to model geodetic data in this region the role of the mechanical heterogeneity of the solid Earth must be quantified. The existence of the Chilean trench near the icefields suggest that enormous lateral viscosity variations may play a role in interpreting crustal motion data. Studies in previously glaciated areas like the Barents Sea, Fennoscandia and Laurentia demonstrated that lateral viscosity variations are important if the geodetic observation point is colocated with strong lateral gradients in mechanical strength at depth [e.g. Kaufmann and Wolf, 1996; Kaufmann et al., 2000; Wu, 2006].

The area of interest is located south of the Chile Triple Junction where crustal volcanism is associated with the formation of a slab window, as is evidenced by the affinity of the adakitic petrology of andesitic rocks of the Andean Austral Volcanic Zone (AVZ) [Stern and Kilian, 1996]. These are derived from an enriched mantle source, possibly due to the anatexis of the subducting slab. The plate reconstruction by Cande and Leslie [1986] shows the age of ridge subduction increasing from the Chile Triple Junction southward reaching an age of $12 \mathrm{Ma}$ at $50^{\circ} \mathrm{S}$. The youthful upwelling of enriched mantle material and the relatively low subduction rate of 1-2 cm/a [Cande and Leslie, 1986; Ramos, 2005] characterize the mechanical slab environment.

The North and South Patagonia Ice Fields (NPI and SPI) are the Neoglacial remnants of the Pleistocene Patagonian Ice Sheet [Naruse et al., 1995; McCulloch et al., 2000]. The aerial extent of these icefields fluctuated on an intercentennial timescale during mid- to late-Holocene time [Aniya, 1995; Lliboutry, 1998; Ivins and James, 1999; Glasser et al., 2004]. Whereas the nearly circular NPI is located just southeast of the Chile Triple Junction, the SPI forms along a narrow band of $350 \mathrm{~km}$ length and $50 \mathrm{~km}$ width parallel to the Chilean coast (Fig. 1). Present-day rapid isostatic rebound south of the Chile Triple Junction $\left(46.5^{\circ} \mathrm{S}\right)$, with preliminary uplift rates near $20 \mathrm{~mm} /$ a reported by Bevis et al. [2006], imply a rather low-viscosity mantle asthenosphere in this region [Ivins and James, 1999, 2004]. 
One goal of this paper is to find diagnostic tests of the mechanical contrast beneath the SPI using crustal motion predictions. The region is characterised by relatively warm aseismic subduction and, possibly complex, long-term mantle flow. In order to explore the possible influence on the load induced displacement field, two different features will be considered: a subducting slab and a localised back-arc mantle wedge. The features will be analysed on a EW profile at $50^{\circ} \mathrm{S}$ perpendicular to the Chilean trench and the AVZ (dashed line in Fig. 1).

\section{Numerical Method}

The field equations governing the deformation process of a self-gravitating, viscoelastic and incompressible continuum of unperturbed density, $\varrho_{0}$, are respectively the equation of motion formulated in the Lagrangian domain, the Poisson equation defining the gravitational forces, the Maxwell constitutive equation and the material-incompressibility condition:

$$
\begin{aligned}
& \operatorname{div} \boldsymbol{\tau}-\varrho_{0} \operatorname{grad} \phi_{1}+\operatorname{div}\left(\varrho_{0} \boldsymbol{u}\right) \operatorname{grad} \phi_{0} \\
& -\operatorname{grad}\left(\varrho_{0} \boldsymbol{u} \cdot \operatorname{grad} \phi_{0}\right)=0 \\
& \nabla^{2} \phi_{1}+4 \pi G \operatorname{div}\left(\varrho_{0} \boldsymbol{u}\right)=0 \\
& \dot{\boldsymbol{\tau}}=\dot{\boldsymbol{\tau}}^{E}-\frac{\mu}{\nu}(\boldsymbol{\tau}-\Pi \boldsymbol{I}) \\
& \boldsymbol{\tau}^{E}=\Pi \boldsymbol{I}+2 \mu \boldsymbol{\varepsilon}
\end{aligned}
$$

$$
\operatorname{div} \boldsymbol{u}=0
$$

Here, $\boldsymbol{\tau}, \boldsymbol{\tau}^{E}$ are the Cauchy stress tensor and its elastic part, $\boldsymbol{I}$ is the identity tensor, $\varrho_{0}$ the reference density, $\boldsymbol{u}$ the displacement vector, $\phi_{0}, \phi_{1}$ the reference gravitational potential and its increment, $G$ the gravitational constant, $\Pi$ the pressure increment, $\mu$ the shear modulus, $\nu$ the dynamic viscosity, and $\varepsilon$ the strain tensor. Boundary conditions at internal surfaces are the continuity of the displacement, normal stress, gravity potential and gravity:

$$
\begin{aligned}
& {[\boldsymbol{u}]_{-}^{+}=0, \quad[\boldsymbol{n} \cdot \boldsymbol{\tau}]_{-}^{+}=0,} \\
& {\left[\phi_{1}\right]_{-}^{+}=0,\left[\left(\operatorname{grad} \phi_{1}+4 \pi G \varrho_{0} \boldsymbol{u}\right) \cdot \boldsymbol{n}\right]_{-}^{+}=0,}
\end{aligned}
$$

where $\boldsymbol{n}$ is the normal of the internal surface. The external surface load, $\sigma$, provides a contact force (pressure) and maintains a surface-gravitational potential. These increments 
define the boundary conditions on the surfaces of the sphere:

$$
\begin{aligned}
\boldsymbol{e}_{r} \cdot \boldsymbol{\tau}^{-} \cdot \boldsymbol{e}_{r} & =-g_{0}(a) \sigma, \\
\boldsymbol{\tau}^{-} \cdot \boldsymbol{e}_{r}-\left(\boldsymbol{e}_{r} \cdot \boldsymbol{\tau}^{-} \cdot \boldsymbol{e}_{r}\right) \boldsymbol{e}_{r} & =0, \\
{\left[\phi_{1}\right]_{-}^{+} } & =0, \\
{\left[\operatorname{grad} \phi_{1}\right]_{-}^{+} \cdot \boldsymbol{e}_{r}+4 \pi G \varrho_{0}^{-}\left(\boldsymbol{u}^{-} \cdot \boldsymbol{e}_{r}\right) } & =4 \pi G \sigma,
\end{aligned}
$$

where $\boldsymbol{e}_{r}$ is the unit vector in radial direction. The equations are solved in the weak formulation by the variation of the corresponding energy functionals which demands two further uniqueness conditions. These are respectively stationarity of the center of mass and absence of net rotation of the body, $B$ :

$$
\begin{aligned}
\int_{B} \boldsymbol{u} \varrho_{0} d V & =0, \\
\int_{B}\left(\boldsymbol{e}_{r} \times \boldsymbol{u}\right) d V & =0 .
\end{aligned}
$$

The time dependence is handled with an explicit time-differencing scheme. For details of the numerical scheme we refer to Martinec [2002].

One constraint in this formulation is that the initial state is hydrostatically pre-stressed, i.e. stresses attributable to the subduction process are neglected. We refer to this as a static-slab approximation. The equations are solved for an axisymmetric configuration requiring the viscosity and load structure to obey the same symmetry. The elasticity and density distribution is spherically symmetric. The radial resolution is $2.5 \mathrm{~km}$ and $5 \mathrm{~km}$ in the lithosphere and in the upper mantle, respectively. The spectral resolution in the lateral direction is $n_{\max }=1024$ which is equivalent to a wavelength of $20 \mathrm{~km}$. The load model and features of the earth model representing the subducting slab is described in the next section.

\section{Earth Structure and Glacial Loading}

For the present study, we consider the loading only from the last two Neoglacial lateHolocene advances of the SPI as described by Glasser et al. [2004]. Incorporation of the earlier Llanquihue glacial sequence, representing the largest of the Pleistocene glaciations, was shown by Ivins and James [2004] to have an insubstantial contribution to the PTuplift prediction. The mass change used from Ivins and James [2004] is based on a simple geometrical treatment by Ivins and James [1999] (Fig. 2). The SPI will be represented by 
a ring load on the spherical earth, where the co-latitudinal radius of the ring is $60.25^{\circ}$ and the width $65 \mathrm{~km}$ is kept constant. The heights are considered from the characteristics of the SPI. The co-latitude was chosen in order to reduce a latitudinal motion of the whole ring produced by the change of its radius on the spherical surface.

The geometry of the slab structure is constrained by this architecture as well, and therefore, the slab-structure also assumes a concentric ring structure (Fig. 3).

The structure represents the main features of the southern Chilean subduction of the Antarctic plate under the South American plate. The assumed thickness of the young elastic oceanic lithosphere of the Antarctic plate is $40 \mathrm{~km}$ and we neglect any increase in thickness with age. The thickness of the elastic continental lithosphere is assumed to be $80 \mathrm{~km}$. From $500 \mathrm{~km}$ east to the trench, we consider a linear decrease of the lithosphere thickness to $40 \mathrm{~km}$. The subducting slab is characterised by a constant angle of $20^{\circ}$ and a constant thickness. The depth at which the slab ceases to exist is chosen in the reference model to be $100 \mathrm{~km}$. The assumption of this rather weak slab structure is supported by the lack of any intermediate-depth (depth $>50 \mathrm{~km}$ ) earthquakes beneath Puerto Natales $\left(51.8^{\circ} \mathrm{S} / 72.5^{\circ} \mathrm{W}\right)$, implying aseismic subduction (Douglas Wiens, pers. comm.). The focal depths of all but one event shown in Fig. 1 are 10 or $33 \mathrm{~km}$ and recorded since 1986 with magnitudes larger than 3 .

To study the influence of the slab in detail, its depth extent is considered a free parameter in the model. The structural assumptions incorporate consideration of the forarc mantle wedge as a zone of reduced viscosity between the slab and the upper crust (from $170 \mathrm{~km}$ to $280 \mathrm{~km}$ on the profile) and, consideration of a possible low-viscosity ductile layer near the base of the continental crust. The viscosities of these zones were assumed to be $10^{18} \mathrm{~Pa}$. This lithospheric structure is embedded in a viscous asthenosphere of $10^{19} \mathrm{~Pa} \mathrm{~s}$ with depth extent to $135 \mathrm{~km}$, roughly consistent with the $120 \mathrm{~km}$ depth suggested by a study of regional seismic anisotropy [Maurice et al., 2003]. Beneath the low-viscosity asthenosphere, a standard spherical earth structure is assumed, consisting of an upper mantle with $5 \times 10^{20} \mathrm{~Pa} \mathrm{~s}$, a lower mantle with $5 \times 10^{21} \mathrm{~Pa}$ s and an inviscid core.

We also account for the possibility of no mechanical slab, with only a wedge below the axis of Neogene-age AVZ intrusives. The latter model is one end member among competing structure models [e.g. Helffrich et al., 2002]. 


\section{Response of Slab to Deglaciation}

First we discuss the main features of the deformation field driven by the loading process. Figure 4 shows the displacement field in the cross section of Fig. 3 at present time (PT). This aids identifying the main features governing the loading process. The response of the earth to the glacial loading is controlled by the elastic flexure of the lithosphere and the buoyant flow of deep viscous material. The time scales of the loading process are rather short in relation to the characteristic times to reach a static equilibrium. Therefore, our solution at PT is meerly a 'snap shot' of a transient process, the final fate of which is to reach this equilibrium. Below the load, the material is principally displaced in vertical direction, whereas a secondary lateral material displacement focusses flow into a relatively weak asthenosphere. In the environment of the asthenosphere a strongly asymmetric pattern appears, which is influenced by the subducting slab. The slab effectively guides the material of the wedge to the continental side. A relatively muted transport toward the oceanic side is promoted by the pronounced bending of the slab. This asymmetry is also displayed in the vertical displacement rate (Fig. 5), where substantial uplift rates at the load centre are predicted due to ongoing deglaciation with a narrow negative peak and positive maximum on both sides. The influence of realistic 2-d mechanical structure is mainly exhibited in the amplitude of the prediction at the forbulges, whereas the prediction at the load axis are the same as in a 1-d earth model with $60 \mathrm{~km}$ lithosphere thickness and $10^{18} \mathrm{~Pa}$ s asthenosphere viscosity.

Figure 6 shows the pressure increment,

$$
p:=-I_{1}(\boldsymbol{\tau}) / 3
$$

and the maximum shear stress,

$$
\sigma^{\mathrm{d}}:=\sqrt{-I_{2}\left(\boldsymbol{\tau}^{\mathrm{d}}\right)}
$$

for the present-time state with $I_{1}$ the first invariant of the stress-tensor increment, $\boldsymbol{\tau}$, and $I_{2}$ the second invariant of its deviatoric part, $\boldsymbol{\tau}^{\mathrm{d}}:=\boldsymbol{\tau}-I_{1}(\boldsymbol{\tau}) / 3$. The scalar $\sigma^{\mathrm{d}}$ is formally known as the maximum shear stress in 3-d plastic failure theory (Malvern, 1969 p. 338; Ivins et al., 2003).

The stress pattern of the lithosphere represents that of a flexed plate showing, below the load, compression at the top of the lithosphere and dilatation at the bottom, flanked by regions exhibiting stress perturbations of the opposite sign. The stress state of the slab 
is dominated by compression, only at the wedge corner, and the slab tip, are dynamic pressures of opposing sign predicted. The location of the wedge directly beneath the SPI is an important factor in amplifying the deformation field and in promoting brittle-failure at the base of the elastic crust. The latter is due the combination of increased shear stress with dilatation (see the blue zones at about $220-280 \mathrm{~km}$ on the profile in Fig. 6 for both the pressure and shear-stress plots). The rapid flow inside the wedge contributes to the stress concentration. As a consequence, the model provides a testable prediction for the spatial pattern of earthquakes in southern Patagonia. The viscous mantle material is in a compressional state and, consistent with the essential constitutive properties of Maxwell material, the shear stresses have largely faded away.

An initial step toward isolation of the underlying physics is to determine the effect of slab length, with other rheological features like the forarc wedge or a DCL are neglected in the model. Figure 7 shows three examples of the varying slab length. The top frame shows the predicted displacements for a slab penetrating deeper than the asthenosphere, terminating inside the higher-viscosity upper mantle. The middle frame shows predictions for a slab terminating inside the asthenosphere and finally, the bottom frame shows the field when only a reduction of lithosphere thickness from continent to ocean is considered. This sequence of frames illustrates how the slab impedes the lateral material transport to the oceanic side. For the model with the penetrating slab, the continuum flow is dominantly toward the continental interior. The displacement into the oceanic environment is controlled by the bent slab, fixed to the lithosphere and to the more viscous upper mantle. For the model with the slab terminating inside the asthenosphere, the slab may more readily flex like a tongue. This enables more material to be displaced toward the oceanic side, and consequently, the displacement rates are slightly enhanced at the loading centre and at the site of the maximum fore bulge (Fig. 8). The model without a slab (Fig. 7, bottom) shows the highest amplitudes in both displacement and surface displacement rates. An asymmetric pattern is predicted, where more material is now displaced toward the oceanic environment. This is due to the fact that the weak asthenospheric channel is thicker beneath the oceanic lithosphere, enabling a more efficient material transport.

The asthenospheric viscosity influences the overall displacement field within its interior. Consequently, it logically follows that relatively higher displacements and rates are 
predicted at PT for a lower viscosity. It must be remarked that there exists a trade off between asthenospheric viscosity and thickness, and this physics partly controls the amplitude and direction of material flux.

It is more difficult to predict what physics controls the influence of a low-viscosity wedge. One would expect that its largest influence is on the displacement rates directly within the volume of the wedge, which would be coincident with the zone below the load in this study. In contrast, comparing Fig.s 4 and 7, the solutions reveal that a much wider area is influenced and that the amplitude of the whole displacement field is enhanced by about a factor of two. The same behaviour is found for the displacement rates comparing the amplitudes of Fig.s 5 and 8. This behaviour is explained by the fact that flux of the low-viscosity wedge material into the asthenosphere promotes more widespread lateral transport.

Naturally, the details of the isostatic flow associated with the wedge that penetrates into the lower crust must also influence the character of the fore bulge in the vicinity of the load. This influence leads to the prediction of rates having narrower dimensions with steep gradients and having higher amplitude. Again, a large asymmetry is predicted. Much of this owes to the slightly asymmetric position of the wedge (Fig. 3).

\section{Summary}

The present study qualitatively reveals the influence of differing, but quite realistic, features of the subduction zone of southern Chile on the predicted displacements induced by the loading due to mass changes in the South Patagonia Ice Field. The overall displacement for this Neoglacial scenario is rather small, not exceeding 10 to $12 \mathrm{~m}$. This seems to imply a negligible, or small, influence of the glacial loading on tectonic processes, except that a particular pattern of enhanced seismicity at PT is predicted. Although the distribution of seismicity around the SPI shown in Fig. 1 suggests a correlation in space with the loading process, further progress requires earthquakes located with a regional array. Most notably, the influence of the slab geometry on the load-induced displacement rate is remarkably strong. The slab geometry results in an asymmetric displacement field. The crust just above the wedge is predicted to be more susceptible to brittle failure in this static-slab approximation. Depending on the length of the slab and its depth of penetration into the mantle asthenosphere, the isostatic response-related material transport is 
restricted by existence of the slab. The fore-arc mantle wedge, resulting in a low viscosity zone directly below the load, not only enhances the displacement rates in this region, but also promotes rates in the surroundings where larger mantle viscosities are likely to exist. Therefore, previous solutions for the asthenosphere viscosity using a 1-d earth structure [e.g. Ivins and James, 2004; Larsen et al., 2005] could be underestimated since 1-d models cannot account for wedge controlled flow.

Figure 9 shows our predicted horizontal motions are of the same order as the regional rate of convergent tectonic motion $(\sim 1-2 \mathrm{~cm} / \mathrm{a})$. The predicted values are between $\pm 0.5 \mathrm{~cm} / \mathrm{a}$ and, consequently, complicate systematic strategies for recovering plate motions from GPS measurements. For example, near-coast tectonic motion might be underestimated while overestimated by up to $50 \%$ if measured east of the Andean mountain peaks.

A strong diagnostic test of mantle structure is seen in the prediction of horizontal motion at the $2 \mathrm{~mm} / \mathrm{a}$ level at the Atlantic coast for the case of wedge, but no slab (solid line, Fig. 9). The latter case would correspond to the regional model proposed by Helffrich et al. [2002]. There, an eastward long-term Pacific mantle flow advects material toward the Atlantic, homogenizing sub-Patagonian asthenosphere. The isostatic models here are perturbations to such longer time-scale flows.

In order to resolve the influence of the modeled structure on the displacement rate field, a spatially dense set of observations along an EW profile with a resolution at the $\mathrm{mm} / \mathrm{a}$ level is required. The relatively intense gradients in strain rate near the edge of the SPI suggest the possible use of interferometric synthetic aperture radar (InSAR). Both, the rugged topography to the west and the net differential amplitudes ( $>10 \mathrm{~mm} / \mathrm{a})$ makes this a quite challanging observation using repeat-pass radar interferometry. Examination of possible dynamic coupling of glacial-isostatic and longer time-scale tectonic processes will demand a more complex field theory of a non-hydrostatic pre-stressed continuum. This, however, is a critical step if considering transient-like features owing to higher order linear viscoelastic response or to non-linear rheology. The aspect ratio of the SPI's lateral geometry is only $\sim 1: 7$ (Fig. 1) and the depth of the subducting slab might increase from the Chile Triple Junction to the south [Cande and Leslie, 1986]. These features demand the modeling of a 3-d rheology and slab structure, though improved seismic constraints would complement such an effort. 
The primary motivation for such modeling, however, should manifest itself as a natural companion to the crustal motion data, relying on the spatial and temporal fidelity of the geodetic results. Some lessons derived from our numerical experiments apply to other subduction zone environments where surface loading is known to cause a measurable gravitational elasto-viscous response, such as in Cascadia, northwestern Honshu and in southeastern Alaska. Load and subduction zone geometry in the latter regions may lack the axial symmetry that we have exploited for Patagonia and a fully 3 -d earth of lateral variations in strength may be appropriate. One of the questions raised in the study of episodic seismicity and creep associated with subduction of young oceanic lithosphere in Cascadia by Dragert et al. [2001] concerns the mechanical strength and integrity of the slab itself. In other words, are very young slabs effectively elastic, viscous, or both? In general, the wedge and slab geometry and the mechanical strength contrasts are capable of producing a greater variety of complexity in the crustal motion response than might be predicted prior to performing the numerical experiments presented in this paper.

Acknowledgments. Part of this research was carried out at the Jet Propulsion Laboratory, California Institute of Technology, under a contract with NASA, and funded through NASA's Earth Surface and Interior Focus Area, Science Mission Directorate. The research by VK was supported by the priority program SPP 1257 of the German Research Foundation DFG. The data of the ANSS/CNSS worldwide earthquake catalogue are contributed by the Advanced National Seismic System (ANSS). Helpful conversations with Mike Bevis, Reinhard Dietrich, Tom James, Jens Wendt and Doug Wiens are most kindly acknowledged. The Graphics program GMT [Wessel and Smith, 1991] was employed.

\section{References}

Aniya, M. (1995), Holocene glacier chronology in Patagonia: Tyndal and Upsala glaciers, Arctic Alpine Res., 27, 311-322.

Bevis, M., E. Kendrick, R. Smalley, R. Barriga, G. Cassasa, R. O'Connell, J. Normandeau, D. Angermann, and J. Klotz (2002), Geodetic observation of postglacial rebound in Patagonia, in IAG Symposium in VII International Congress in Earth Sciences, Digital Files, Santiago, edited by n/a. 
Bevis, M. G., E. Kendrick, H. Zhou, R. J. Smalley, G. Casassa, H. Parra, and E. Lauria (2006), Has the recent tectonic history of Patagonia equipped it with an anomalous viscoelastic response to changing ice loads?, in Backbone of the Americas? Patagonia to Alaska, (3-7 April 2006, Mendoza, Mendoza Province), edited by n/a, 13-7, Geological Society of America, Paper.

Bird, P. (2003), An updated digital model of plate boundaries, Geochem. Geophys. Geosyst., 4, doi:10.1029/2001GC000252.

Cande, S. C., and R. B. Leslie (1986), Late Cenozoic tectonics of the southern Chile trench, J. Geophys. Res., 91, 471-496.

Dragert, H., K. Wang, and T. S. James (2001), A silent slip event on the deeper Cascadia subduction interface, Science, 292, 1525-1528.

Glasser, N. F., S. Harrison, V. Winchester, and M. Aniya (2004), Late Pleistocene and Holocene palaeoclimate and glacier fluctuations in Patagonia, Global Planet. Change, 43, 79-101.

Helffrich, G., D. A. Wiens, E. Vera, S. Barrientos, P. Shore, S. Robertson, and R. Adaros (2002), A teleseismic shear-wave splitting study to investigate mantle flow around South America and implications for plate-driving forces, Geophys. J. Int., 149, F1-F7.

Ivins, E. R., and T. S. James (1999), Simple models for late Holocene and present-day Patagonian glacier fluctuations and predictions of a geodetically detectable isostatic response, Geophys. J. Int., 138, 601-624.

Ivins, E. R., and T. S. James (2004), Bedrock response to Llanquihue Holocene and present-day glaciation in southernmost South America, Geophys. Res. Lett., 31, L24613, doi:10.1029/2004GL021500.

Ivins, E. R., T. S. James, and V. Klemann (2003), Glacial isostatic stress shadowing by the Antarctic ice sheet, J. Geophys. Res., 108, 2560, doi:10.1029/2002JB002182.

Kaufmann, G., and D. Wolf (1996), Deglacial land emergence and lateral upper-mantle heterogeneity in the Svalbard Archipelago - II. Extended results for high-resolution models, Geophys. J. Int., 127, 125-140.

Kaufmann, G., P. Wu, and G. Li (2000), Glacial isostatic adjustment in Fennoscandia for a laterally heterogeneous earth, Geophys. J. Int., 143, 262-273.

Larsen, C. F., R. J. Motyka, J. T. Freymueller, K. A. Echelmeyer, and E. R. Ivins (2005), Rapid viscoelastic uplift in southeast Alaska caused by post-Little Ice Age glacial re- 
treat, Earth Planet. Sci. Lett., 237, 548-560.

Lliboutry, L. (1998), Glaciers of the wet Andes, in Glaciers of South America, edited by R. S. Williams and J. G. Ferrignio, no. 1386-I in U. S. Geol. Surv. Prof. Pap., pp. 148-206, USGS.

Malvern, L. E. (1969), Introduction to the Mechanics of a Continuous Medium, 713 pp., Prentice-Hall, Englewood Cliffs.

Martinec, Z. (2002), Semi-analytical solution for the viscoelastic relaxation in spherical earth with an axisymmetric craton, Acta Geod. Geophys. Hung., 37, 61-78.

Maurice, S. D. R., D. A. Wiens, K. D. Koper, and E. Vera (2003), Crustal and upper mantle structure of southernmost South America inferred from, regional waveform inversion, J. Geophys. Res., 108, 2038, doi:1029/2002JB001828.

McCulloch, R. D., M. J. Bentley, R. S. Purves, N. R. J. Hulton, D. E. Sugden, and C. M. Clapperton (2000), Climatic inferences from glacial and palaeoecological evidence at the last glacial termination, southern South America, J. Quat. Sci., 15, 409-417.

Naruse, R., M. Aniya, P. Skvarca, and G. Casassa (1995), Recent variations of calving glaciers in Patagonia, South America, revealed by ground surveys, satellite-data analyses and numerical experiments, Ann. Glaciol., 21, 297-303.

Ramos, V. A. (2005), Seismic ridge subduction and topography: Foreland deformation in the Patagonian Andes, Tectonophysics, 399, 73-86.

Rignot, E., A. Rivera, and G. Casassa (2003), Contributions of the Patagonia icefields of South America to sea level rise, Science, 302, 434-437.

Siebert, L., and T. Simkin (2002-), Volcanoes of the world: an illustrated catalog of Holocene volcanoes and their eruptions, Global Volcanism Program Digital Information Series GVP-3, http://www.volcano.si.edu/world/, Smithsonian Institution.

Stern, C. R., and R. Kilian (1996), Role of subducted slab, mantle wedge and continental crust in the generation of adakites from the Andean Austral Volcanic Zone, Contrib. Mineral. Petrol., 123, 263-281.

Wessel, P., and W. H. F. Smith (1991), Free software helps map and display data, EOS, Trans. Am. Geophys. Union, 72, 441-446.

$\mathrm{Wu}$, P. (2006), Sensitivity of relative sea levels and crustal velocities in Laurentide to radial and lateral viscosity variations in the mantle, Geophys. J. Int., 165, 401-413. 


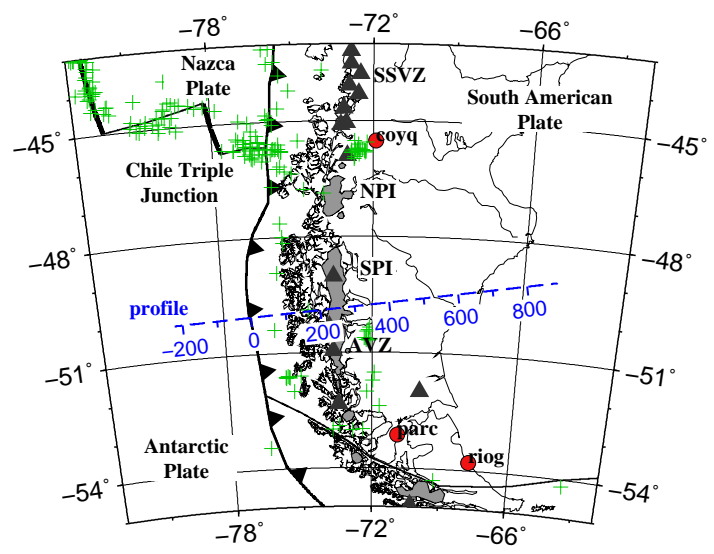

Figure 1. Tectonic setting of southern South America [after Cande and Leslie, 1986]. Plate names, and type of plate boundaries are denoted [from Bird, 2003]. Also shown are the volcanos (triangles) of the southern South Volcanic Zone (SSVZ) and Andean Austral Volcanic Zone (AVZ) [from Siebert and Simkin, 2002-] and, in grey, the present ice coverage of the North and South Patagonia Ice Fields (NPI and SPI) [from McCulloch et al., 2000]. Blue dashed line marks the profile considered in this study with distance measured im $\mathrm{km}$ from trench. Locations of IGS stations and their code are added as red circles, Green crosses denote seismic events for the time period 1986-2006 from the ANSS/CNSS worldwide earthquake catalogue. 


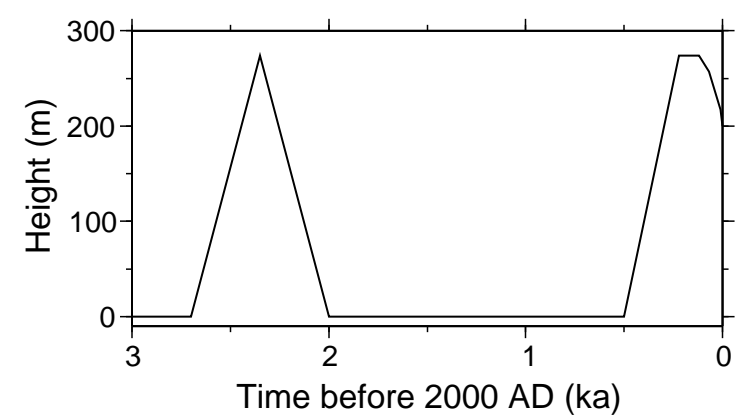

Figure 2. Variation of loading height associated with Neoglacial late-Holocene advances of South Patagonia Ice Field. The unloading accelerates during the late 20th century as described in Ivins and James [2004], following Rignot et al. [2003].
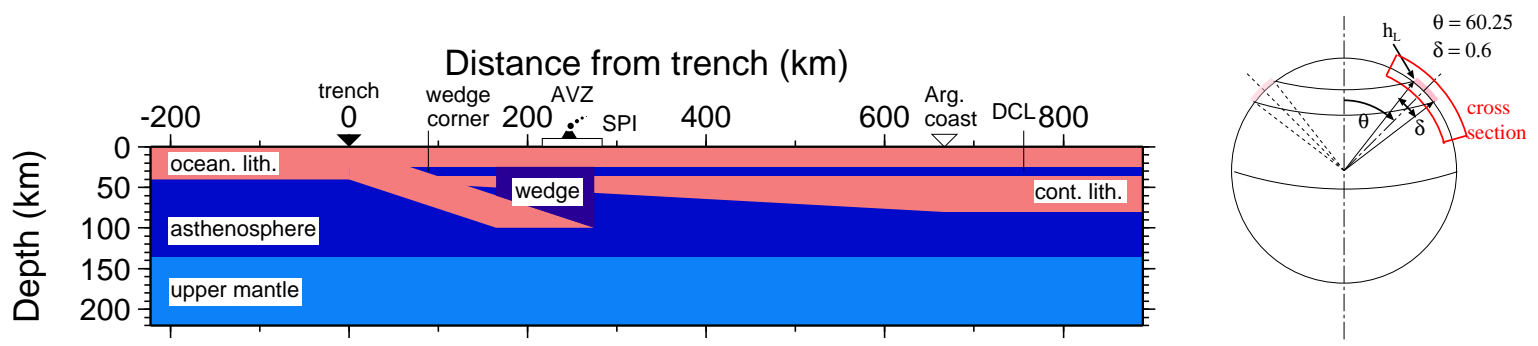

Figure 3. Cross section of the considered earth model in the vicinity of the slab. Highlighted are the main features: the Austral Volcanic Zone (AVZ), the South Patagonia Ice Field (SPI), the Argentinian coast (Arg. coast) and the ductile crustal layer (DCL). The structure is embedded into the spherical geometry (right) where $\theta$ and $\delta$ denote the co-latitude and width of the load, respectively. 


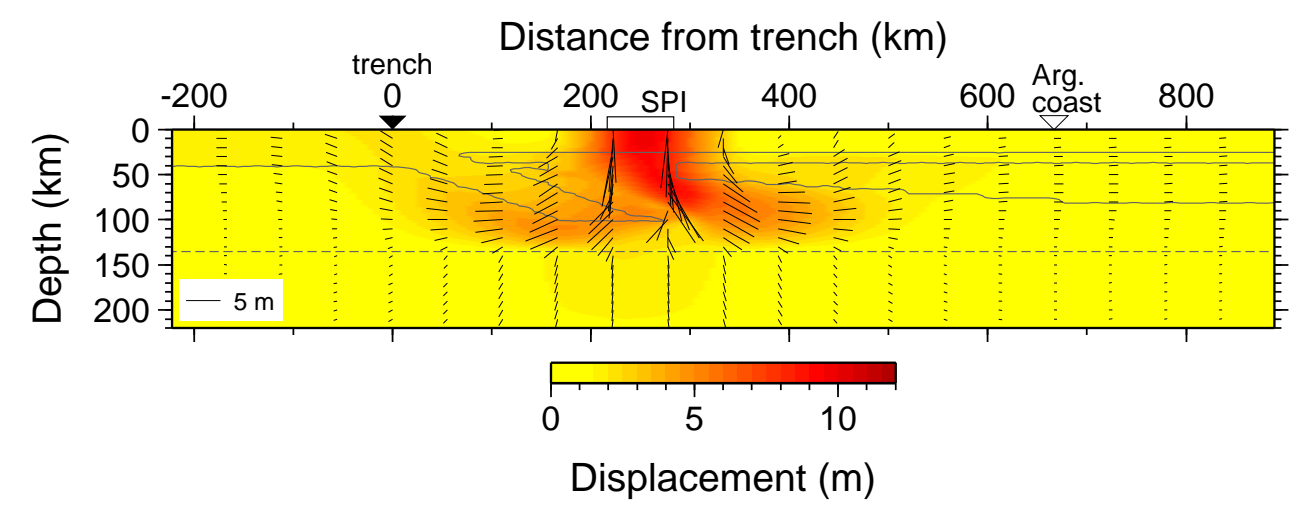

Figure 4. Displacement field of earth model shown in Fig. 3 loaded by the two last Neoglacial advances and retreats. The displacement does not exceed $10 \mathrm{~m}$. Lines denote the amplitude and direction of displacement. Icons denote main features on profile.

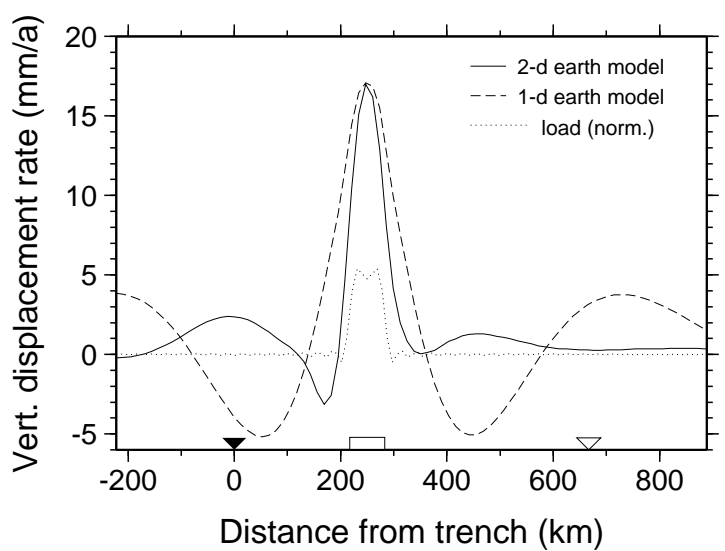

Figure 5. Vertical surface-displacement rate at PT of earth model shown in Fig. 3 loaded by the two last Neoglacial advances. The dashed line is the equivalent prediction with radial stratification only (1-d earth model). Dotted line is the normalized load height. For meaning of icons see Fig. 4. 


\section{Distance from trench $(\mathrm{km})$}

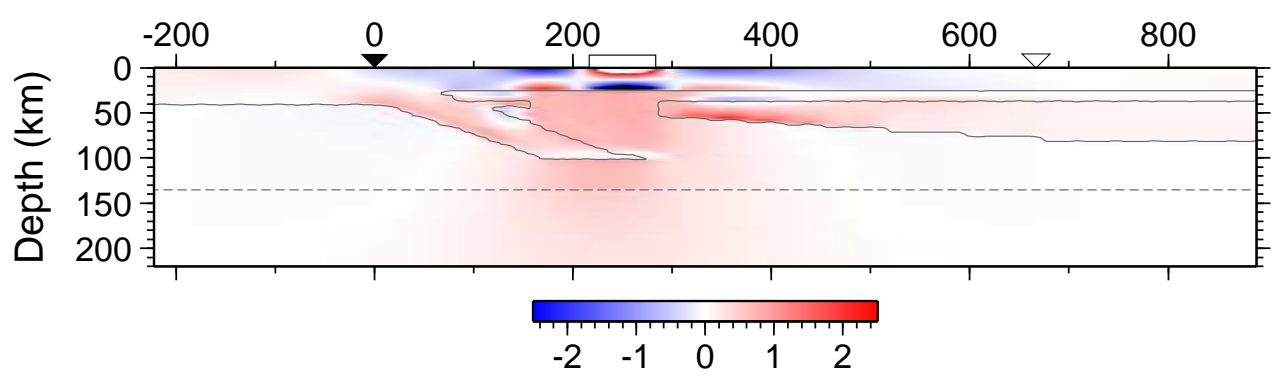

Pressure increment (MPa)

Distance from trench $(\mathrm{km})$

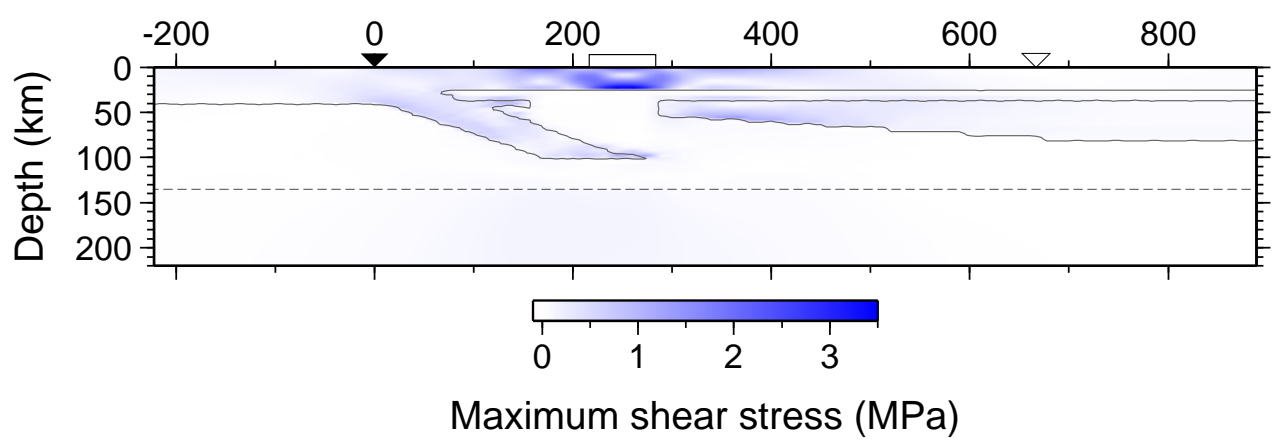

Figure 6. Cross section of PT stress field for earth model shown in Fig. 3 induced by the deformation of the modeled Neoglaciation. Top panel shows the pressure increment, $p$, bottom panel the maximum shear stress, $\sigma^{\mathrm{d}}$. For meaning of icons see Fig. 4. 


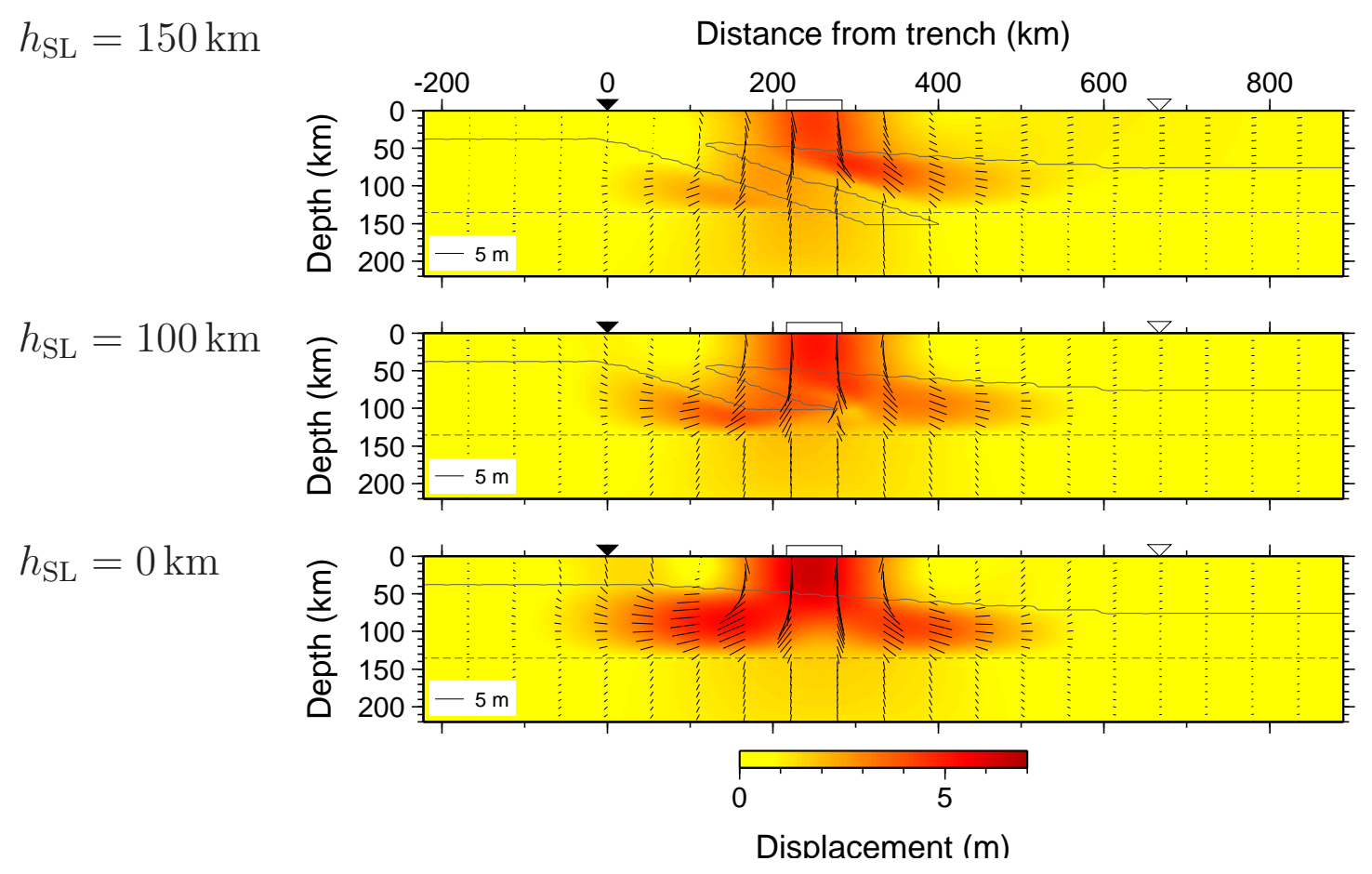

Figure 7. Displacement field in the upper mantle from top to bottom for models with slab penetrating deeper than the asthenosphere, with slab terminating inside the asthenosphere and without a slab, respectively. Grey lines denote the asthenosphereupper mantle boundary (dashed) and the boundaries between the elastic parts of the slab and the lithosphere to viscous material (solid). For meaning of icons see Fig. 4.

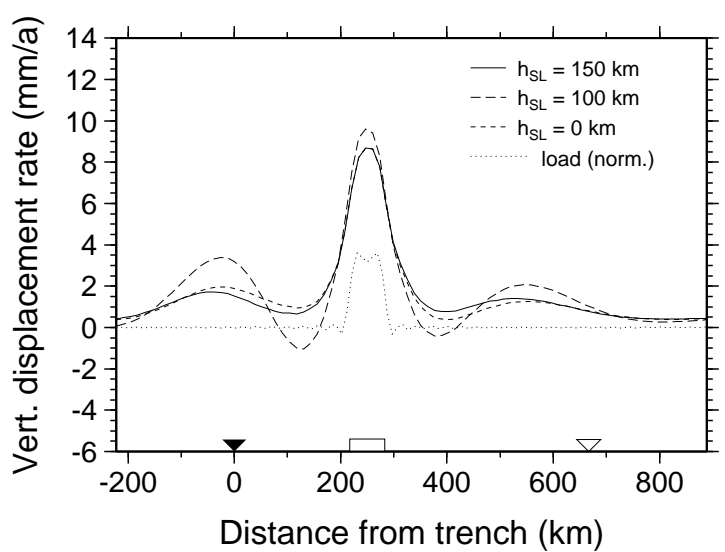

Figure 8. Vertical surface-displacement rate at PT for the models shown in Fig. 7. For meaning of icons see Fig. 4. 


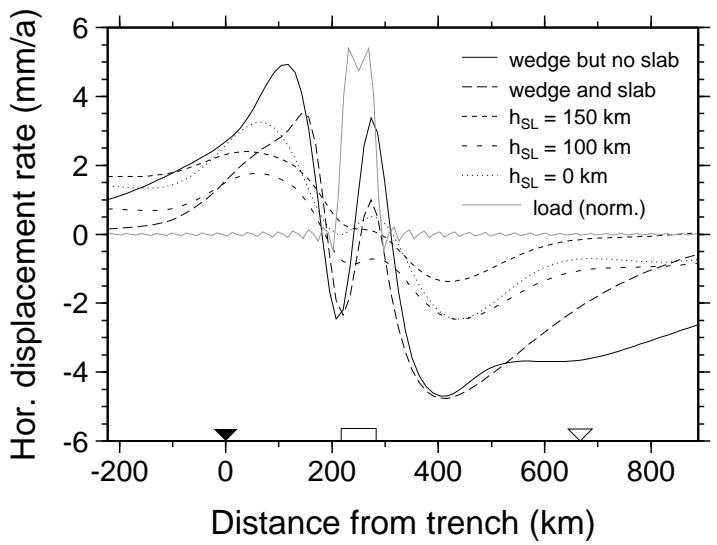

Figure 9. Horizontal surface-displacement rate at PT for the models considered in this study. Positive values mean a displacement rate to the right, and negative values to the left. For meaning of icons see Fig. 4. 